Article

\title{
Surface Wear in Hadfield Steel Castings DOPED with Nitrided Vanadium
}

\author{
Konstantin Vdovin, Alexander Pesin * (1), Nikolay Feoktistov and Dmitri Gorlenko \\ Metallurgy, Mechanical Engineering and Materials Processing Institute, Nosov Magnitogorsk State Technical \\ University, 38, Lenina Prospect, Magnitogorsk 455000, Russia; vdovin@magtu.ru (K.V.); fna87@mail.ru (N.F.); \\ gorldima@yandex.ru (D.G.) \\ * Correspondence: pesin@bk.ru; Tel.: +7-351-906-3056
}

Received: 3 September 2018; Accepted: 10 October 2018; Published: 18 October 2018

\begin{abstract}
This paper examines possible industrial applications of high manganese steel and the feasibility of its inoculation with a new ferroalloy, vanadium nitride. The abrasive and impact-abrasion surface wear experienced by castings has a classical pattern: microcutting-i.e., the deformation twinning of surface layers. Ferrovanadium nitride enhances the surface resistance of castings both as a cast and as thermally treated. A fine grain structure is formed in the surface layers, specifically layers in direct contact with abrasive particles. The deformation twins that are present at the solid solution grain boundaries tend to change their orientation and characteristics. The impact-abrasion wear also leads to hardened layer formation at the working surface due to deformation twinning. The carbides (nitrides) present in the surface wear do not produce any significant impact on the process of deformation twinning. As the wear line extends deeper into the casting surface, the carbides and nitrides are ripped out and cavities occur in the wearing zone. The wear is controlled by the solidification rate. Thus, at lower rates a hardened layer is formed, which accommodates adjacent areas with differing twin characteristics, such as orientation and spacing.
\end{abstract}

Keywords: high manganese steel; austenite; carbides; wear resistance; twinning

\section{Introduction}

High manganese cast steel (also known as Hadfield steel) is an austenitic alloy with high wear resistance. It is quite often used as a cast steel in the mining industry [1,2]. Sand and metal molds are used for high manganese steel castings.

The structure of the as-cast Hadfield steel consists of austenite and excess carbides, which are responsible for enhanced ductility and wear resistance. In almost every case, the steel is subjected to quenching [3]. In the high manganese steel grade 110G13L, the pure austenitic structure is observed in the temperature range of 910 to $1392{ }^{\circ} \mathrm{C}$. The Hadfield steel castings are only rarely subjected to machining as they are not easily workable due to the hardening effect that can occur during cutting and the resultant accelerated wear of the tool.

In Russia, the chemical composition of this steel is specified by the National Standard (abbreviation "GOST"), and the composition adopted abroad is quite similar [4]. The analysis of data on Hadfield steel available in the literature shows that the foreign producers of high manganese steel products can have differing views regarding the chemical composition of high manganese steel.

It is possible to make a significant change to the properties of high manganese steel by adding various elements [5-11] through the process of inoculation. The wear experienced by high manganese steel castings is governed by a combination of multiple factors, such as the chemical composition of the alloy, the qualitative and quantitative parameters of the microstructure, and the mechanical properties. The above factors are interrelated-for example, a change in the chemical composition changes the microstructure of the castings, resulting in changed mechanical properties and performance [12-14]. 
An important wear factor is a second phase, which precipitates during solidification and, following heat treatment, is present in the microstructure of high manganese steel. Moreover, depending on the chemical composition of the alloy and the casting temperatures, the precipitation of inclusions of carbides, nitrides, phosphide eutectic, and others is possible as the second phase, whereas the inclusions of one type can have different concentrations of chemical elements, which will define their properties, including wear resistance (in particular as a response to abrasive and impact-abrasion wear). In the case of steel primarily used as cast steel in the mining industry, the above process poses both an important and underexplored research area [15-19]. Thus, the objective of this study was to understand the surface wear experienced by high manganese steel castings inoculated with ferrovanadium nitride.

\section{Materials and Methods}

The experimental alloys were produced by the foundry laboratory of Nosov Magnitogorsk State Technical University in $60 \mathrm{~kg}$ and $2 \mathrm{~kg}$ induction furnaces with basic lining. The high manganese Hadfield steel for castings was produced using standard furnace charge and common ferroalloys (Table 1).

Table 1. Common ferroalloy, Grade FV35N9: Chemical Composition.

\begin{tabular}{cccccccccccc}
\hline Element & $\mathbf{N}$ & $\mathbf{V}$ & $\mathbf{S i}$ & $\mathbf{M n}$ & $\mathbf{S}$ & $\mathbf{P}$ & $\mathbf{C}$ & $\mathbf{A l}$ & $\mathbf{T i}$ & $\mathbf{C a}$ & $\mathbf{F e}$ \\
\hline Concentration, mass \% & 7.6 & 40.4 & 8.5 & 2.3 & 0.04 & 0.04 & 0.34 & 0.01 & 0.03 & 0.03 & 40.75 \\
\hline
\end{tabular}

The experimental alloys were reduced with aluminum in the ladle. The SPECTROMAXx optical emission spectrometer (SPECTRO Analytical Instruments $\mathrm{GmbH}$, Kleve, Germany) was used to analyze the chemical composition of the castings. Molds with different heat-retaining capacities were used for castings; the castings produced had different weights, which delivered specimens applicable for testing within a broad range of cooling temperatures. The specimens had a minimum size of $35 \times 35 \times 10 \mathrm{~mm}^{3}$ and a maximum size of $50 \times 50 \times 50 \mathrm{~mm}^{3}$.

The metal temperatures were measured with a tungsten-rhenium thermocouple; results were recorded on an LA-50USB device (JSC "Rudnev-Sheeljaev", Moscow, Russia), which had $50 \mathrm{~Hz}$ per channel and was capable of recording to four channels at the same time.

The wear resistance of the alloys was analyzed in reference to GOST 23.208-79, "Test Method for Resistance to Wear by Rubbing the Specimen against Loose Abrasive Grit." The specimen was pressed with a force of $44.1 \pm 0.25 \mathrm{~N}$ against a rubber roller rotating at $60 \pm 2 \mathrm{RPM}$ and moving abrasive particles across the surface of the specimen. Steel 45 was taken as a reference steel, and alundum with a grit size of $0.16 \mathrm{~mm}$ was used as an abradant (Figures 1 and 2). The wear resistance index was calculated using a simple formula; the specimens were weighed with an Acculab electronic scale with an accuracy of $\pm 0.0001 \mathrm{~g}$. The test was performed at least three times.

The testing machine used to study impact-abrasion resistance was designed to induce multiple collisions between a specimen and a counter-specimen, with a dosing unit feeding an abradant between the two specimens at the moment of collision.

The castings were heat treated in an electric resistance furnace Nakal (JSC “Nakal - Industrial furnaces", Moscow, Russia) equipped with an electronic module enabling stage heating. Heat treatment procedure: water quenching from $1100^{\circ} \mathrm{C}$. The specimens were kept in the furnace for $15 \mathrm{~min}$ from the moment the temperature in the working zone reached $1100^{\circ} \mathrm{C}$. 


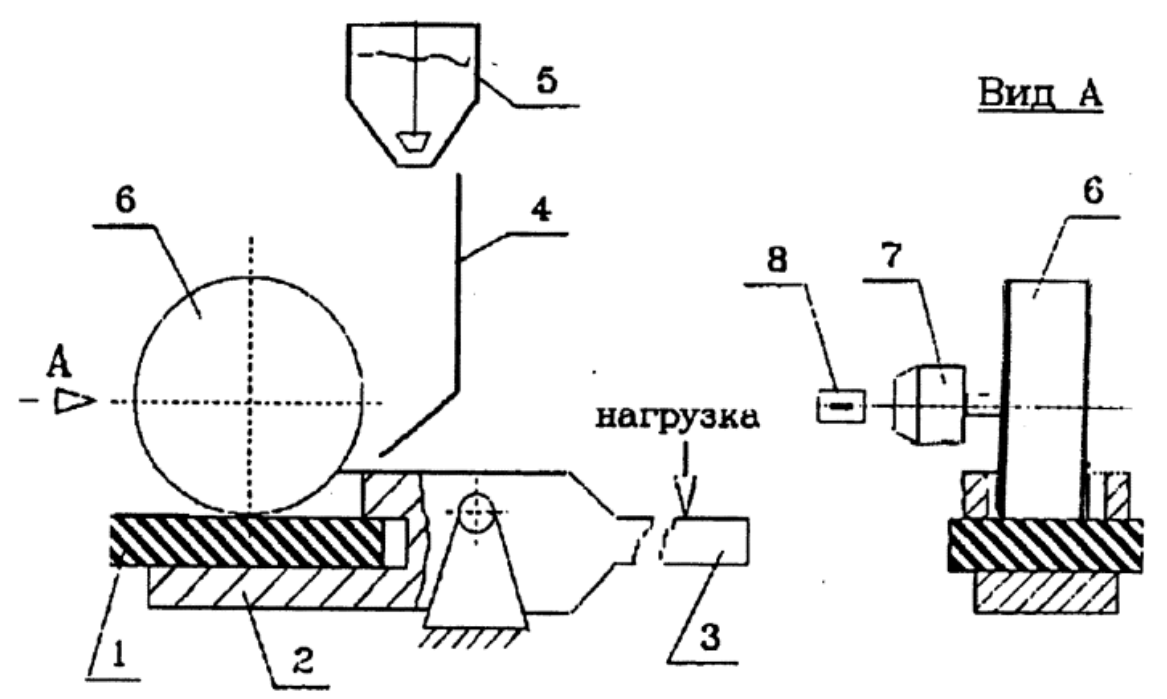

Figure 1. Equipment for wear testing: 1: sample; 2: sample holder; 3: lever; 4: guide tray; 5: measuring hopper; 6: roller; 7: drive; 8: counter of roller turns.

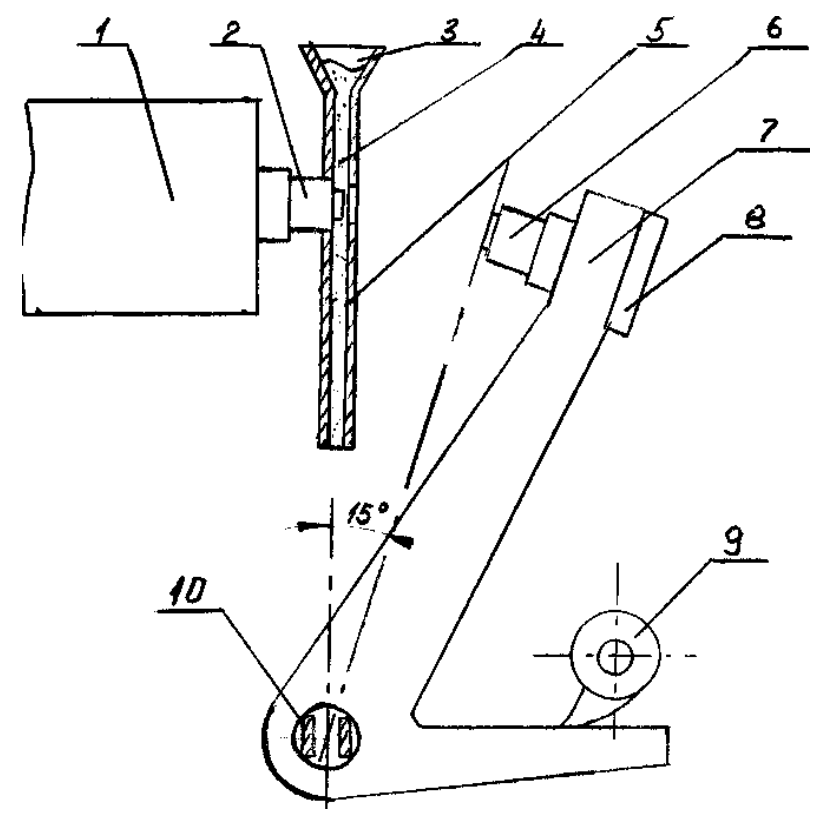

Figure 2. Sketch of the testing machine for the impact-abrasion wear testing (designations are explained in the text).

As seen in Figure 1a, the testing machine used to study impact-abrasion resistance consisted of a sample holder (1) and a weight holder (2), which WERE used to control the impact velocity when sample (1) hit the wear bushing (3) of the anvil (4) with an inaccuracy not exceeding $2.5 \%$. It also included a unit with changeable torsion bars (5), which limited the inaccuracy of the created impact energy to $2.5 \%$ at the minimum torsion angle of $15^{\circ}$, and a striker (6) with a given directional moment of inertia. A cam (7) created a given slope of the striker.

The grain size was analyzed and the quantitative analysis was performed using a Meiji optical microscope (MEIJI TECHNO CO., LTD, Saitama, Japan) with a Thixomet Pro software (ver. 1.0, Thixomet ltd., Russian) following the GOST 5639-82 standard. For microstructural characterization, the slices with polished surfaces were immersed in a $4 \%$ nitric acid and ethanol solution as an etching treatment.

For scanning electron microscopy, an electron microscope, JEOL JSM-6490 LV (JEOL, Ltd., Tokyo, Japan), was operated at an accelerating voltage of $20 \mathrm{kV}$. Transverse microsections, which are 
commonly used in light microscopy, were analyzed in a secondary electrons mode with $\times 30$ to $\times 50,000$ magnification. The X-ray microanalysis was accomplished using an INCA (Oxford Instruments plc, Belfast, UK), Energy system, a special add-on to a scanning microscope JEOL JSM-6490 LV. The X-ray diffraction analysis was accomplished on a Shimadzu (SHIMADZU CORPORATION, Kyoto, Japan) XRD-7000 X-ray diffractometer with a chromium anode at $40 \mathrm{kV}$ and $30 \mathrm{~mA}$.

The dimensions of the deformation twins were analyzed using a NanoEducator (NT-MDT Spectrum Instruments Group, Moscow, Russia) scanning probe microscope with a resolution of $0.3 \mathrm{~nm}$, in the $X$ and $Y$ axes, and that of $0.03 \mathrm{~nm}$ in the $Z$ axis.

The microhardness testing was performed under the GOST 9450-60 standard with the help of a Buehler Mikromet (Buehler, An ITW Company, Lake Bluff, IL, USA) microhardness tester; this tester had a diamond pyramid indenter with a $136^{\circ}$ angle between opposite faces, and was subjected to a load of $200 \mathrm{~g}$ for $10 \mathrm{sec}$. The hardness of the specimens was tested with a EmcoTest M4C $075 \mathrm{G3}$ (EMCO-TEST Prüfmaschinen GmbH, Kellau, Austria) hardness tester, under the GOST 9450-60 standard.

The Hadfield cast steel was inoculated with ferrovanadium nitride in a furnace. The material was charged into the crucible as one charge. The furnace temperature during charging was between 1540 and $1560{ }^{\circ} \mathrm{C}$. The vanadium recovery rate was at 67.5 to $71.8 \%$.

Table 2 shows the mold type and the specimen weight in relation to the Manganese steel cooling rates.

Table 2. The mold type and the specimen weight in relation to cooling rates.

\begin{tabular}{ccccc}
\hline \multirow{2}{*}{ Specimen } & Mold Type & Weight, kg & \multicolumn{2}{c}{ Cooling Rate in the Internal, ${ }^{\circ} \mathbf{C} / \mathbf{s}$} \\
\cline { 4 - 5 } & & & Crystallization & Excess Phase Precipitation \\
\hline 1 & Dry green sand & 0.5 & 1.1 & 0.24 \\
2 & Dry green sand & 0.34 & 1.9 & 0.35 \\
3 & Dry green sand & 0.21 & 3.7 & 0.4 \\
4 & Dry green sand & 0.1 & 4.5 & 1.0 \\
5 & Dry green sand w/ cold box & 0.05 & 8.9 & 1.8 \\
6 & Dry green sand w/ cold box & 0.05 & 13.6 & 3.27 \\
7 & Wet green sand & 0.1 & 17.9 & 4.25 \\
8 & Chill mold & 0.1 & 25.0 & 5.45 \\
\hline
\end{tabular}

\section{Results}

As part of the experimental study, the amount of the ferroalloy introduced in the melt was increased from 0.3 to $1.4 \%$ by weight. This was accompanied with a reduction in the nitrogen recovery rate from 95 to $50 \%$ (Figure 3), irrespective of the cooling rate. The resultant castings were found to have the same nitrogen concentration, between $0.023 \%$ and $0.062 \%$, even though the cooling regimes differed.

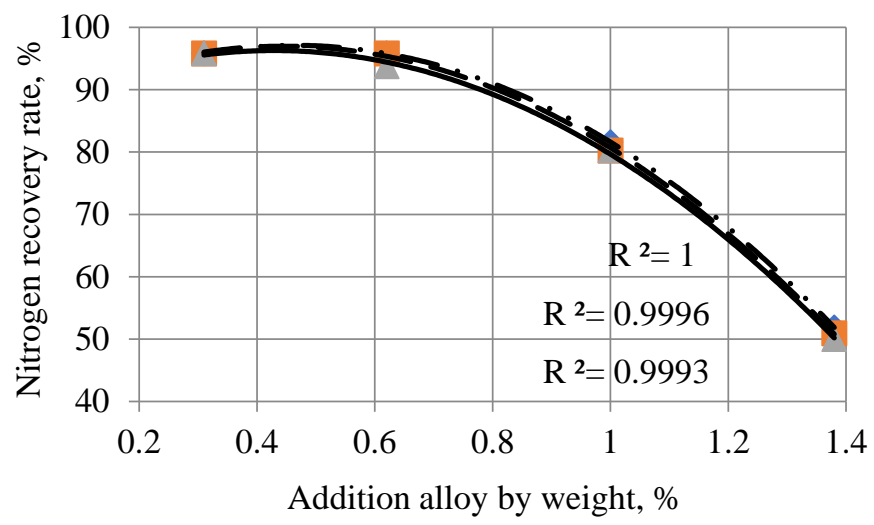

Figure 3. Nitrogen recovery rate in high manganese steel at cooling rates within the crystallization interval: $-\cdots-4.5^{\circ} \mathrm{C} / \mathrm{s}$; - - - $-8.9^{\circ} \mathrm{C} / \mathrm{s} ;-25^{\circ} \mathrm{C} / \mathrm{s}$. 
Specimens with $0.29 \%$ of vanadium (Figure 4 ) and specimens with $0.175 \%$ and $0.29 \%$ of ferrovanadium nitride (Figures 5 and 6) were used to study abrasive and impact-abrasion wear and the related surface hardening mechanism.

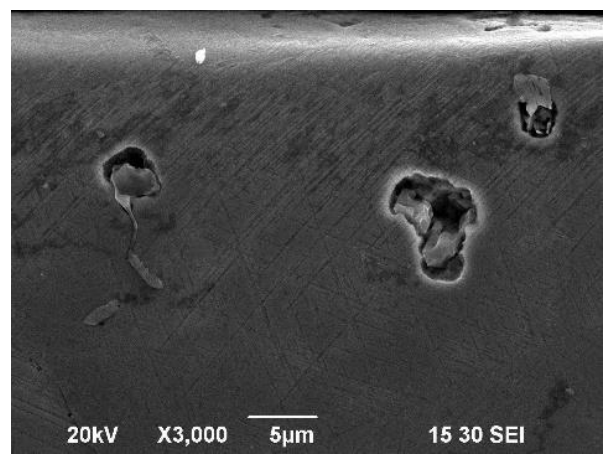

(a)

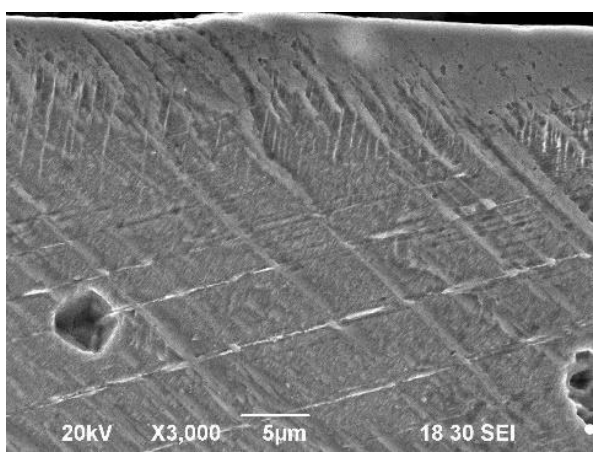

(b)

Figure 4. Wear surface microstructure, $0.29 \% \mathrm{~V}$ : (a) as cast; (b) after heat treatment.

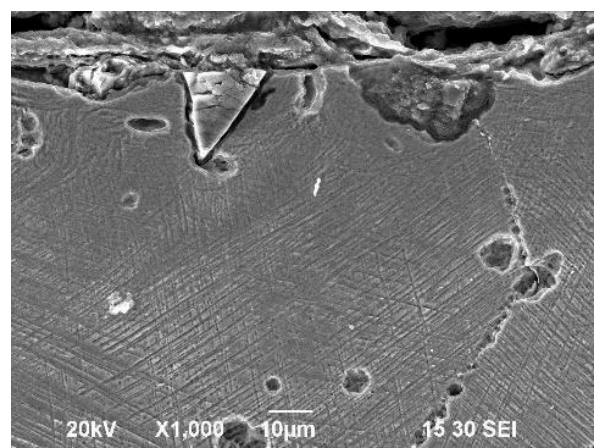

(a)

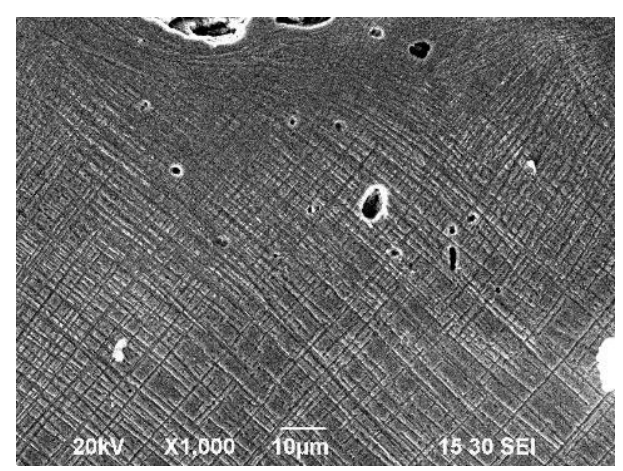

(b)

Figure 5. Microstructure of $0.175 \% \mathrm{~V}$ high manganese steel surface subjected to impact-abrasion wear: (a) as cast; (b) after heat treatment.

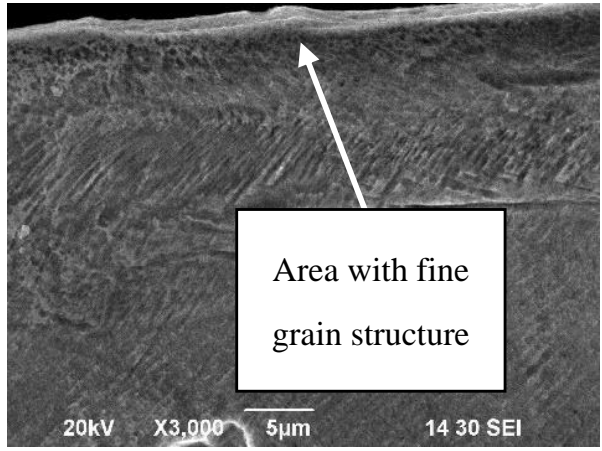

(a)

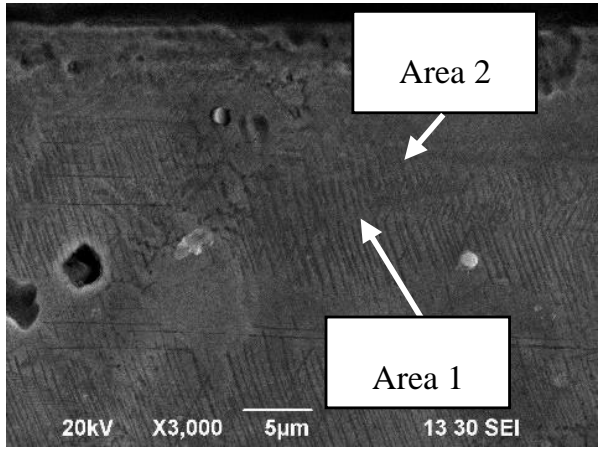

(b)

Figure 6. Wear surface microstructure, $0.29 \% \mathrm{~V}$ : (a) as cast; (b) after heat treatment.

\section{Discussion}

The wear mechanism followed a classical pattern: microcutting-i.e., the deformation twinning of surface layers. Figures 3-5 show boundaries in as-cast and heat-treated castings that are typical of deformation twins. The boundaries ran parallel to each other, changing their orientation in particular surface areas. The contact surface (the wear zone) formed a layer with a fine grain structure, which was an interlayer between the abradant and the layer of the alloy deformation twinning. 
When nitrogen was used as an alloying element, the carbides (nitrides) present in the wear surface did not produce any significant impact on the deformation twinning processes. As the wear line extended deeper in the casting surface, the carbides and nitrides were ripped out and cavities occurred in the wearing zone (Figure 7).

In the case of lower crystallization rates in the liquidus-solidus temperature ranges and precipitation of a proeutectoid constituent $\left(4.5\right.$ and $\left.1.0^{\circ} \mathrm{C} / \mathrm{sec}\right)$, the wear surface microstructure was different from the one observed in castings, which experienced higher rates of crystallization and cooling. However, the key differentiating feature was related to the extra layers that formed in microstructures, having deformation twins substantially different from those occurring in the adjacent layers (Figure 6).

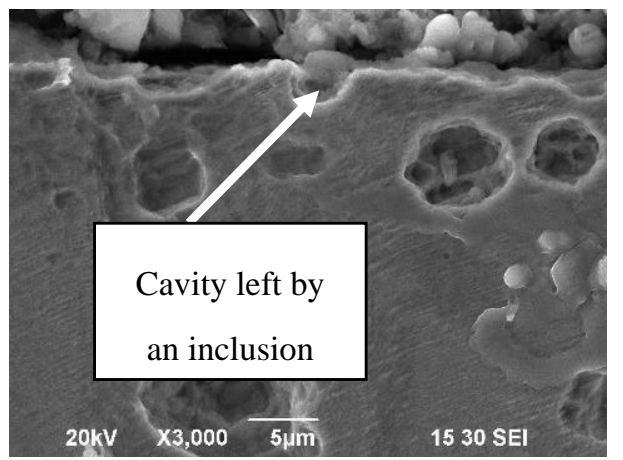

(a)

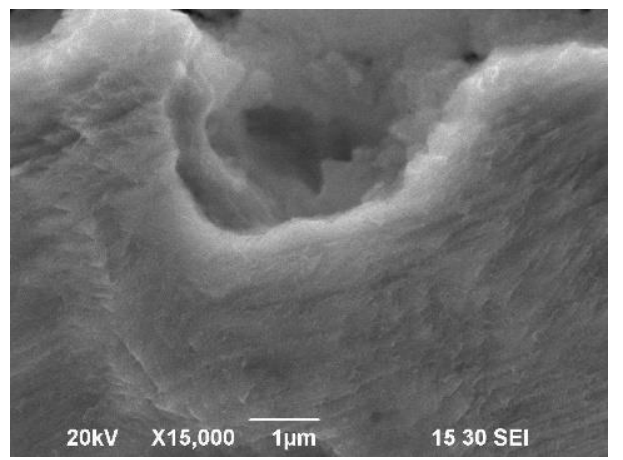

(b)

Figure 7. Wear surface in high manganese steel castings doped with ferrovanadium nitride: (a) general view; (b) cavity left by a carbide (nitride).

As Figure 6, Areas 1 and 2, demonstrate, microstructures can have layers where either the deformation twin boundaries change their orientation or the spacing changes between the boundaries. Whereas the surface layers, i.e., the layers that come in direct contact with the abradant, form fine grain structures (Figures 6 and 8). The grain (block, fragment, and subgrain) size typically do not exceed $1 \mu \mathrm{m}$, although the grain size may change from 50 to $270 \mu \mathrm{m}$, depending on the solidification rate.

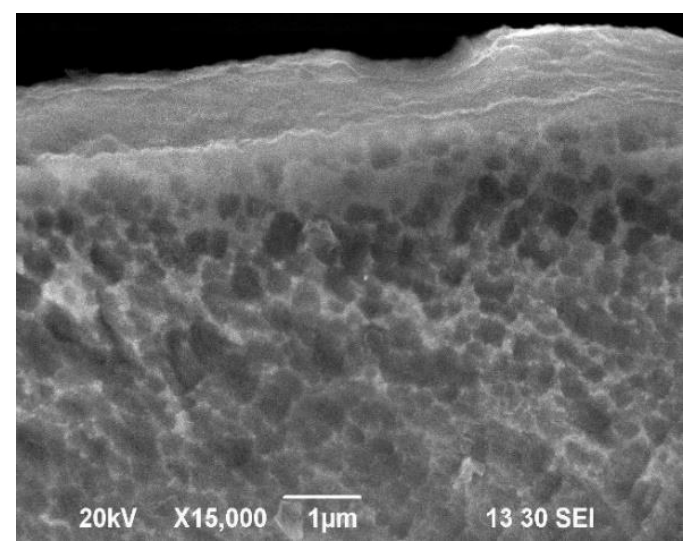

Figure 8. Working surface layer in contact with the abradant $(0.29 \% \mathrm{~V}$, cooling rate within the crystallization interval $\left.4.5^{\circ} \mathrm{C} / \mathrm{s}\right)$.

The deformation twins characteristics and changed orientation were observed at the solid solution grain boundaries (Figure 9). 


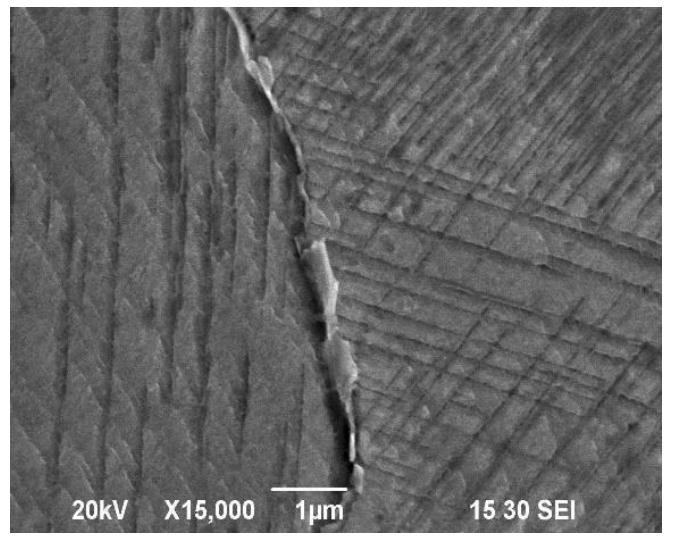

Figure 9. Deformation twins at the austenite grain boundaries.

Impact-abrasion wear lead to the formation of hardened layers through deformation twinning, which occured in the working surface of both as-cast and heat-treated castings (Figure 4).

\section{Conclusions}

Following a series of laboratory experiments and tests performed on castings to analyze resistance to abrasive and impact-abrasion wear, it was established that ferrovanadium nitride can help enhance the surface wear resistance in both as-cast and heat-treated castings. Furthermore, it was established that the enhanced surface wear resistance was due to deformation twinning. A fine grain structure was formed in the area that came in contact with the abradant, with the predominant grain size not exceeding $1.0 \mu \mathrm{m}$ and the twins changing their orientation at the grain boundaries. Lower cooling rates caused a hardened layer to form, which accommodated adjacent areas with differing twin parameters-i.e., orientation and spacing. Moreover, the carbides (nitrides) present in the wearing zone ripped out of their seats, leaving small cavities.

Author Contributions: All authors contributed equally to this study.

Funding: This research was funded by [the Russian Science Foundation] grant number [No. 15-19-10020].

Acknowledgments: We thank A. A. Nefed'iev for his participation in this research.

Conflicts of Interest: The authors declare no conflict of interest.

\section{References}

1. Sinitskyi, Y.V.; Nefed'iev, A.A.; Akhmetova, A.A.; Ovchinnikova, M.V.; Hrenov, I.B.; Deryabin, D.A. Review of results of investigation aimed at improvement of properties of castings made from high manganese steel. Theor. Technol. Steelmak. 2016, 2, 42-57.

2. Davydov, N.G. High Manganese Steel; Metallurgiya: Moscow, Russia, 1979; p. 176.

3. Chumanov, I.V.; Porsev, M.A. On the effect of the chemical composition of metal on the heat treatment regimes applied for 110G13L steel castings. Bull. State Ural State Univ. 2012, 39, 59-63.

4. Chernyshev, E.A. Cast Alloys and Their Foreign Counterparts; Mashinostroenie: Moscow, Russia, 2006; p. 336.

5. Kreshchanovskyi, N.S.; Ladyzhenskyi, B.N.; Khorin, Y.D. Steel Melting and Steel Castings; TsNIITMASH: Moscow, Russia, 1960; pp. 77-82.

6. Kozlov, L.Y.; Kolokoltsev, V.M.; Vdovin, K.N. Production of Steel Castings: Textbook for University Students; MISiS: Moscow, Russia, 2005; p. 351.

7. Golubtsov, V.A. Theory and Practice of Extra-Furnace Steel Doping; NPP Company: Chelyabinsk, Russia, 2006; p. 423.

8. Shitikov, V.S.; Gederevich, N.A.; Sherstyuk, A.A.; Kurbatov, M.I. Effect of titanium on the gas saturation, surface properties and quality of high manganese steel. Prod. Technol. Manag. 1971, 3, 57-58. 
9. Nasajpour, A.; Kokabi, A.H.; Davami, P.; Nikzad, S. Effect of molybdenum on mechanical and abrasive wear properties of coating of as weld Hadfield steel with flux-cored gas tungsten arc welding. J. Alloys Compd. 2016, 659, 262-269. [CrossRef]

10. Mejía, I.; Bedolla-Jacuinde, A.; Pablo, J.R. Sliding wear behavior of a high-Mn austenitic twinning induced plasticity (TWIP) steel microalloyed with Nb. Wear 2013, 301, 590-597. [CrossRef]

11. Lyakishev, N.P.; Tulin, N.A.; Pliner, Y.L. Alloys and Niobium Containing Steels; Metallurgiya: Moscow, Russia, 1981; p. 192.

12. Mirzaev, D.A.; Koryagin, Y.D.; Okishev, K.Y. Effect of metallurgical factors on the mechanical and wear properties of cast manganese steels. Izv. Chelyabinskogo Nauchnogo Tsentra Bull. Chelyabinsk Sci. Cent. 1999, 3, 18-22.

13. Gorlenko, D.; Vdovin, K.; Feoktistov, N. Mechanisms of cast structure and stressed state formation in Hadfield steel. China Foundry 2016, 13, 433-442. [CrossRef]

14. Jiang, Q.; He, Z.; Cui, D.; Wang, S.; Yan, J. Abrasion-resistant as-cast manganese steel with nodular carbide modified by calcium. J. Mater. Sci. Lett. 1990, 9, 616-617.

15. Atabaki, M.M.; Jafari, S.; Abdollah-pour, H. Abrasive wear behavior of high chromium cast iron and Hadfield steel-A comparison. J. Iron Steel Res. Int. 2012, 19, 43-50. [CrossRef]

16. Petrov, Y.N.; Gavriljuk, V.G.; Berns, H.; Schmalt, F. Surface structure of stainless and Hadfield steel after impact wear. Wear 2006, 260, 687-691. [CrossRef]

17. Yan, W.; Fang, L.; Zheng, Z.; Sun, K.; Xu, Y. Effect of surface nanocrystallization on abrasive wear properties in Hadfield steel. Tribol. Int. 2009, 42, 634-641. [CrossRef]

18. Kolokoltsev, V.M.; Vdovin, K.N.; Chernov, V.P.; Feoktistov, N.A.; Gorlenko, D.A. Understanding the Mechanical and Wear Properties of High Manganese Steel Doped with Nitrided Frochromium. Vestnik Nosov Magnitogorsk State Tech. Univ. 2016, 3, 46-54. [CrossRef]

19. Bochkov, V.S. Use of Cold-Working Techniques for Enhanced Wear Resistance of Ball Mill Liners as Part of the Maintenance Routine. Ph.D. Thesis, Saint-Petersburg Mining University, Saint Petersburg, Russia, 2014; p. 119.

(C) 2018 by the authors. Licensee MDPI, Basel, Switzerland. This article is an open access article distributed under the terms and conditions of the Creative Commons Attribution (CC BY) license (http:/ / creativecommons.org/licenses/by/4.0/). 